\title{
EXPLORING A FORWARD DESIGN DIMENSION IN THE DESIGN OF SCHOOL-BASED KISWAHILI TEACHING SYLLABI FOR PRIMARY SCHOOLS IN UGANDA
}

Caesar Jjingo, Makerere University

Marianna Visser, Stellenbosch University

'We live today in difficult, uncertain and complex times...citizens have to be prepared to adapt to different contexts. So, in this rapidly changing world... knowledge must also be comprehensive and based on multiple capabilities.' (Galvão, Faria, Freire \& Baptista, 2017:

In Uganda, delays in teaching and learning of Kiswahili in primary schools have been experienced since their establishment in the education systems in the 1920s. At present, the language-in-education policy requires the National Curriculum Development Centre (NCDC) to prepare instructional materials for facilitating the teaching of Kiswahili as a compulsory subject from primary schools to secondary schools. However, the NCDC has been able to produce and launch the Kiswahili teaching syllabi for secondary schools only, delaying the introduction of the teaching syllabi for primary schools. This theoretical paper argues that the absence of a Kiswahili conventional syllabus in primary schools has led teachers to (i) abandon the teaching profession as Kiswahili language teachers, and (ii) attempt 'designing' individual-based (hereafter, school-based) syllabi. The paper intends to demonstrate how the quality of the existing school-based syllabi can be improved and also aims to demonstrate (to language teaching researchers, advisers and language teachers) in general, how teachers can design their respective school-based syllabi purposefully to strengthen the teaching and learning of Kiswahili in their respective schools and classrooms.

Keywords: Forward design dimension, grammar-based syllabus, individual-based syllabus, task-based syllabus, school-based syllabus, Swahili, Uganda

\section{INTRODUCTION}

This theoretically based paper aims to explore and illustrate the application of Richards' (2013) forward design dimension proposals in the design of school-based Kiswahili teaching syllabi for primary schools. It should be noted that, while Richards' proposals are for developing language curriculum, in this paper, his forward design dimension model, which 'means developing a curriculum through moving from input, to process and to output' (Richards, 2013: 8), as demonstrated in later sections of this paper, is employed to provide a basis for Kiswahili teachers in designing syllabi for their respective schools or classes.

This is because Richards (2013: 6) defines a syllabus as a result of decisions on (i) the linguistic content (see input mainly in the second last section of this paper), (ii) how the content is graded and (iii) how the content is logically sequenced as teaching and learning units in the classroom. This definition is largely reflected in the notion of a curriculum, as proposed by Richards (2013). In his study, Richard (2013: 6) refers to a curriculum as 'the overall plan or design for a course and how the content for a course is transformed into a 
blueprint for teaching and learning which enables the desired learning outcomes to be achieved.'

Relatedly, taking into consideration Richards' (2013) views on curriculum and syllabus, Finney (2002: 70) and Graves (2008: 147) contend that the concepts of curriculum and syllabus have often been regarded as synonymous (cf. Nunan, 1991: 3). This is because of, as Finney (2002: 70) points out, the view that curriculum, in a narrow sense, involves 'specification of the content and the ordering of what is to be taught', which defines what a syllabus is, according to Nunan (1991: 6). Therefore, this paper is consistent with, and generally reflects, Finney's (2002: 70) and Richards' (2013: 6) views regarding the definitions of the two concepts (curriculum and syllabus).

In light of the above, it should be remembered that this study was motivated by the fact that the National Curriculum Development Centre (NCDC), responsible for developing and launching the Kiswahili teaching curricula and syllabi in Uganda, has, for instance, unsuccessfully distributed the designed Kiswahili syllabi for primary schools. This situation, which has been observed over time by the first author of this paper, has led Kiswahili teachers to individually design syllabi to facilitate the teaching and learning of Kiswahili as mainly a foreign language (L2) in their respective schools (cf. Republic of Uganda, 2008b: vi).

Views from the scholarly literature (e.g., Msanjila, 2005: 215-216) hold that, for teacher designed syllabi to have sufficient teaching and learning utility and to be in tandem with other instructional materials, the advice of language specialists is required during their design processes. Msanjila's proposals are in agreement with the views of an assistant curriculum specialist from NCDC (P Arinaitwe, personal communication, 15 February 2017). Specialist Arinaitwe (personal communication, 15 February 2017) disclosed to the first author of this paper that, in general, Kiswahili teachers in Uganda do not yet have the expertise to design syllabi. Specialist Arinaitwe (personal communication, 15 February 2017) stated that the NCDC is responsible to train Kiswahili teachers on how to assess and interpret the NCDC's syllabi before they are appointed in schools (cf. Ministry of Education and Sports, 2004: 18).

The above situation regarding lack of sufficient competencies by teachers to design syllabi implies that, in Uganda, concerns on Kiswahili teaching syllabi for primary schools are insufficiently addressed, yet limited studies (e.g., Jjingo, 2018: 5-6; Mukama, 2009: 87) have attempted to generally discuss this issue. In fact, no study exists that has attempted to explore Richards' (2013) dimensions of forward design with regard to designing school-based syllabi, which is the focus of the current paper.

Before we explore the rationale of exploring Richards's (2013) proposals, it is in order to contextualise the issue addressed in this paper by discussing the situation in which the teaching and learning of Kiswahili in primary schools of Uganda are necessitated and considered.

\section{DYNAMICS OF REALISING THE TEACHING AND LEARNING OF KISWAHILI IN PRIMARY SCHOOLS}

'Uganda has made attempts to mainstream the teaching of Kiswahili over the years albeit with little success.... Most recommendations to teach Kiswahili have remained on paper' (NCDC, 2012: 9). This epigraph summarises the situation in which the teaching and learning of Kiswahili as an L2 have largely been viewed in the education systems of Uganda, specifically 
in primary schools, since their introduction in formal education in the 1920s. A point worth noting is that this situation somehow continues to exist even though Kiswahili is being nominated as a second official language (Republic of Uganda, 2005: np, 2006: 7, 2015a: i) of multilingual Uganda (Simons \& Fennig, 2018).

It should be pointed out that, in Uganda, Kiswahili is still considered as a foreign language (cf. Isingoma, 2016: 445). This is because, according to Kiango (2005: 157) and PawlikováVilhanová (2004: 199), Kiswahili spread into Uganda from East African coastal societies by around the first half of the $19^{\text {th }}$ century. Activities in commerce, slavery and religion (mainly Islam) are regarded as key factors in the spread of Kiswahili from the coast to the interior parts of Africa, including Uganda. Subsequently, through such activities, Kiswahili swiftly spread and became the lingua franca of the present-day East and Central African region.

Being a regional lingua franca, Kiswahili was chosen and adopted in the formal education systems that were established by European missionaries mainly in the East African region. For example, in Uganda, a western form of education had been introduced in 1901 (Ssekamwa \& Lugumba, 2000: 2). Pawliková-Vilhanová (1996: 167) suggests that, by the 1920s, the teaching of Kiswahili as an L2 had been included in educational systems of the country. However, for mainly being a foreign language (Mulumba \& Masaazi, 2012: 437; Ssentanda \& Nakayiza, 2017: 107), the inclusion of teaching and learning Kiswahili in the education systems of Uganda has been faced with challenges from the beginning (cf. Jjingo \& Visser, 2017). Scholars such as Mbaabu (2007: 101) and Mukama (2009: 85) state that one primary challenge occurred in 1952 when Kiswahili was formally excluded from the education systems of the country. Until the 1990s, the formal teaching of Kiswahili mainly in primary schools was a forgotten factor.

It should be pointed out that the idea to reinstate the teaching of Kiswahili in Uganda's education system was conceived in the late 1980s. This was after debates about the national language, began once again. While the national language question is still unsolved, these debates partly led to the establishment of the language-in-education policy that, among other things, provides for the compulsory teaching of Kiswahili language from primary schools to secondary schools (Republic of Uganda, 1992: 19-20).

Furthermore, this policy states that one of the implementational strategies of the above postulations regarding the teaching of Kiswahili in schools is the "preparation of required curriculum and instructional materials by the National Curriculum Development Centre on a priority basis and a crash programme, starting from 1992/93' (Republic of Uganda, 1992: 21). In this respect, this paper notes that, while this policy has been fairly well implemented in secondary schools and beyond, its application in the primary schools is still pending, mainly with regard to Kiswahili teaching syllabi (cf. Ministry of Education and Sports, 2017: 60-62; Ssentanda, 2016: 63).

Following the postulations on the teaching of Kiswahili as established in the language-ineducation policy, the NCDC has produced and launched Kiswahili teaching syllabi for lower (Republic of Uganda, 2008b, 2016) and upper (Republic of Uganda, 2014) secondary schools. The launch of the syllabi for secondary schools leaves teachers of Kiswahili in primary schools without a conventional curriculum and syllabus from which to draw the teaching content to teach their learners. Consequently, as some Kiswahili teachers abandon the teaching of Kiswahili in their respective schools, others are compelled by the existing 
situation to opt for 'designing' school-based syllabi to fulfil their teaching responsibilities in their respective schools.

To design such syllabi, Kiswahili teachers mainly use their experience in tandem with available written resources such as English and Kiswahili textbooks that are at their disposal. In fact, as a teacher-trainee, the first author of this paper passed through similar experiences during the teaching practicums (school/teaching practice, as it is known in Uganda) in two different urban schools.

Against this background, the current paper intends to explore and illustrate, with special relevance to Kiswahili teachers in general, how to utilise Richards's (2013) proposals of a forward design dimension in syllabus design. The illustration aims to demonstrate to teachers how they can update and advance the design of school-based syllabi that subscribe to contemporary types of syllabi (e.g., task-based syllabi) with specific reference to focus-onform, as an approach, which incorporates some facets (e.g., focus-on-forms) of grammarbased syllabi.

Literature (e.g., Ellis \& Shintani, 2014: 52; Krahnke, 1987: 15; Nunan, 2006: 13) shows that grammar-based syllabi are widely used for the teaching of L2s. At present in Uganda, for example, grammar-based syllabi are employed in the teaching of English (Republic of Uganda, 2008a) and Kiswahili (Republic of Uganda, 2008b, 2016) as L2s in lower secondary schools. Wilbur (2007: 79) contends that grammar-based syllabi have continuously been used in the classrooms because most L2 teachers have been trained through such syllabi.

\section{THE RATIONALE FOR EXPLORING RICHARDS' PROPOSALS ON THE THREE MAJOR CURRICULUM DESIGN APPROACHES}

Before the actual exploration and subsequent illustration and application of Richards' (2013) proposals, it is necessary to discuss the rationale for viewing the approach advanced by him as appropriate for the Ugandan context for teaching Kiswahili as an L2.

As mentioned in the introduction of this paper, while Richard's proposals are concerned with developing a language curriculum, in this paper, his model is employed to provide a framework as a basis for Kiswahili teachers in designing school syllabi. This is because the steps that Richards (2013) suggests for curriculum development are similar to the steps that are followed in designing focus-on-form lessons or activities, as demonstrated in the secondto-last section of this paper. Several factors were considered by the current authors for choosing Richards's model, but due to space constraints, only a few are further discussed in this paper.

Richards' (2013) proposals were chosen given his influential and contributions in the field of curriculum development and methodology in the teaching and learning of L2s (see, for example, Richards, 1984, 1985, 2001, 2006, 2007, 2008, 2010, 2013, 2015, 2017; Richards \& Lockhart, 1996; Richards \& Renandya, 2002; Richards \& Reppen, 2014; Richards \& Rodgers, 2014, 1982; Richards \& Schmidt, 2010). In addition, Richards's model is a refined version of a commonly employed model of designing grammar-based syllabi, as exemplified in studies including Breen (1987a, 1987b, 2001), Krahnke (1987), and Long and Crookes (1993). As pointed out earlier in this paper, in most countries, even in Uganda, grammarbased syllabi are still used in facilitating L2 teaching and learning. Thus, Richards' model is feasibly positioned to offer its practical applicability in schools such as Uganda's primary 
schools, given that the forward design dimension is composed of components similar to those used to design focus-on-form lessons, as exemplified by Ellis, Basturkmen and Loewen (2002).

Furthermore, according to Breen (1987a: 87), Ellis and Shintani (2014: 53), Krahnke (1987: 15), Long and Crookes (1993: 13), and Nunan (2004: 11), a model like the one of Richards (2013) has often been employed in syllabus design processes and in classroom practices. For instance, Breen (1987a: 87) emphasises that most language teachers are familiar with using such syllabi given teachers' views and experiences about language learning and teaching. In addition, Breen is of the view that learners have successfully acquired L2s based on this type of syllabus design, which suggests, for example, that Uganda's primary school teachers can also attempt to employ Richards' proposal and ascertain its suitability in the facilitation of teaching and learning of Kiswahili in primary schools.

\section{Contextualising the underpinnings of Richards' forward design dimension}

Taking note of the above and in relation to his model, Richards (2013: 7) points out that developing a curriculum for L2 teaching has several dimensions as starting points. In his study, Richards describes and compares three of these dimensions with their starting points: input (syllabus), process (methodology) and output (learning outcome), as diagrammatically summarised in Figure 1.

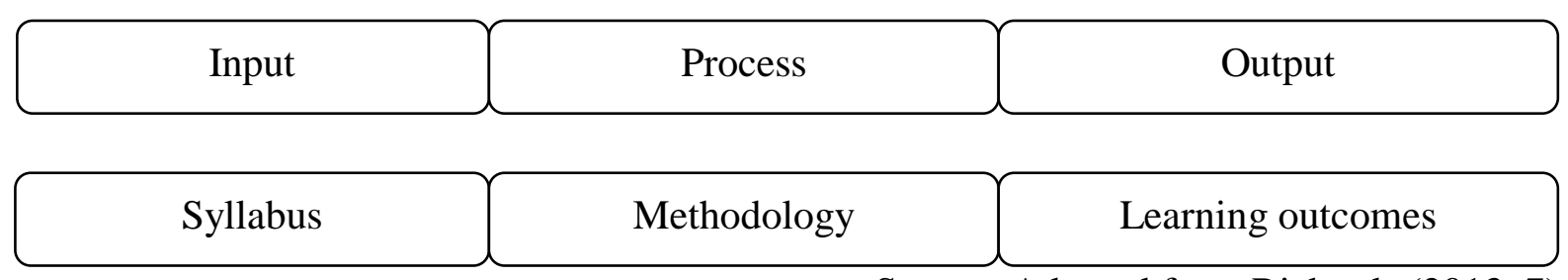

\section{Figure 1: Curriculum dimensions}

Source: Adapted from Richards (2013: 7)

Richards (2013: 7) argues that, while the above components relate to each other, there is a general assumption that these components operate in a linear system while developing curricula, that is to say, from the input component through to the output component (cf. Richards, 2013: 11). In this regard, Richards (2013: 7) advances the view that such an assumption undermines contemporary L2 teaching and learning theories and classroom practices. Nevertheless, Richards (2013: 28) contends that all approaches to curriculum design (in this case, dimensions or starting points of syllabus design) work well in different situations in which they are being employed. In fact, under some circumstances, these approaches can be employed concurrently. Subsequently, each starting point offers different implications for classroom language practices.

Out of the three dimensions, this paper mainly focuses on the input or syllabus dimension, also known as the forward design strategy, as a point of departure to curriculum/syllabus design and development. This was primarily motivated by the assumptions that (Richards, 2013: 29):

A forward design option may be preferred in circumstances where a mandated curriculum is in place, where teachers have little choice over what and how to teach, where teachers rely mainly on textbooks and commercial materials rather than teacherdesigned resources, where class size is large and where tests and assessments are 
designed centrally rather than by individual teachers. Since forward design can be used to develop published materials there will generally be a wide range of teaching resources and materials to choose from. The forward design may also be a preferred option in situations where teachers may have limited...language proficiency and limited opportunities for professional development, since much of the planning and development involved, can be accomplished by specialists rather than left to the individual teacher.

In our opinion, the above assumptions largely confirm and explicitly describe the characteristics related to the teaching and learning of Kiswahili in primary schools in Uganda, as partly observed in the second section of this paper. For example, in Uganda's primary schools, due to the operationalisation of the Universal Primary Education system, studies such as Grogan (2009: 187-188) and the Republic of Uganda (2015b: 27-30) revealed that the ratio of learners to their teachers is still beyond the reasonable average (cf. Tamusuza, 2011).

In addition, due to widespread written resources (school textbooks) in English in Uganda, the authors of this paper contend that there has been an increase in Kiswahili textbooks from Tanzania and Kenya. The topics and the suggested teaching methods drawn from these written materials constitute the content that Kiswahili teachers in Uganda tend to modify to suit the different teaching and learning needs that arise in their daily lessons. Lastly, Richards' (2013: 29) views concerning teachers' lack of language proficiency are in agreement with Mukama's (2009: 85) perspectives that most Kiswahili teachers in Uganda pedagogically and linguistically lack sufficient competence.

Given the above background, this paper attempts to explore and illustrate the employability of the forward design dimension in designing school-based syllabi for primary schools, particularly those in Uganda. To employ this design, this paper assumed that Kiswahili teachers for primary schools need to have a basic background in the Kiswahili language. In addition, more than consulting curriculum and/or syllabus design specialists continuously, by using possible communication channels, language teachers can be in a position to function as syllabus designers (although it can be challenging sometimes, especially in the beginning) who can mainly utilise the available in-print Kiswahili or English language instructional materials. This provides a basis for several opportunities for teachers to have a variety of ideas from which to choose content or topics as they accomplish their obligations of designing syllabi for their classrooms or schools.

\section{ILLUSTRATING SYLLABUS DESIGN IN THE FORWARD DESIGN CURRICULUM APPROACH}

As we illustrate the application of the underpinnings of the curriculum approach characterised by Richards (2013) as a forward design dimension in syllabus design, that is, input, process and output, it is appropriate to provide Kiswahili examples with the aim of contextualising our major concern. In addition, it should be kept in mind that, unlike other dimensions to curriculum design, the dimensions of forward design operate in a linear system regarding the decisions of developing the curriculum and/or syllabus, as illustrated in Figure 2. 




Figure 2: Implementing a forward design dimension

Source: Adapted from Richards (2013: 13)

The above diagram illustrates the process and entails that each stage or step depends on its preceding step or a series of steps. For instance, in this context, decisions related to assessments follow decisions on the outcomes. Similarly, the outcome decisions are considered after decisions on methodology. Furthermore, decisions associated with the content determine the methodology ('however, in theory, a syllabus does not necessarily imply a particular methodology', (Richards, 2013: 11)) decisions. In this way, the forward design dimension has been adopted. For example, it conforms to the contemporary types of syllabi (e.g., task-based syllabi) with specific reference to a focus-on-form approach, which follows a connected linear system and procedure, as exemplified by Ellis et al., (2002).

Thus, having discussed some of Richards's (2013) main underpinnings in relation to the contextualisation of the concern of this paper, we consider Richards' (2013:6) views that, in the history of L2 teaching and learning, the input is the linguistic content of the language that learners are bound to learn. Scholars, including Ellis (2003: 68) and VanPatten (2002: 106107), state that input can be pictorial, oral or written.

With respect to forward design dimensions and Msajila's (2005: 215-216) previously discussed proposals, as employed in this paper, a basic example of input is what this paper generally refers to as principles of Kiswahili grammar 'kanuni za sarufi ya Kiswahili', identified within a focus-on-form approach to teaching Kiswahili as an L2. These include: phonology 'fonolojia', word formation 'uundaji wa maneno', nouns 'nomino', verbs 'vitenzi', adjectives 'vivumishi', pronouns 'viwakilishi', conjunctions 'viunganishi', adverbs 'vielezi', interjections 'viingizi' and sentences 'sentensi', summarised from Kiswahili textbooks and reference materials (Ashton, 1987; Habwe \& Karanja, 2004; Massamba, Kihore \& Hokororo, 1999, 2012; Massamba, Kihore \& Msanjila, 2004; Mohammed, 2001; Mpiranya, 2015).

Richards argues that the choice of linguistic content (i.e., input) comes before any decisions related to teaching a language. Some of the procedures employed to select the input include its simplicity, authenticity, frequency, learnability and usefulness. Krahnke (1987: 15-16) adds the aspect of the familiarity of the input to the language learners as another technique of its selection. For demonstration purposes, this paper has chosen verbs 'vitenzi', from the above list of the principles of Kiswahili grammar, as an example (i.e., input). This is because Kiswahili verbs demonstrate a series of grammatical categories that can be learned by learners at once. According to Richards and Schmidt (2010: 625), these categories include tense, aspect, person, number and mood.

Thus, given that the choice of verbs 'vitenzi' has been selected as facet of input drawn from form-focused activities, it is organised into possible units that can readily be taught to the learners and learned by them, for instance, the characteristics of Kiswahili verbs, namely the structure of Kiswahili verbs, borrowed Kiswahili verbs and different kinds of Kiswahili verbs, as modified from Mohammed (2001: 71-92).

In addition, the above units (e.g., the borrowed verbs) can further be sequenced in a systematic manner to ease their teachings in the language classrooms. In this context, the 
Kiswahili verbs of Arabic origin, such as shukuru 'thank', fasiri 'translate' and samehe 'forgive', are distinguished from the Kiswahili verbs of Bantu origin, such as cheza 'play', pika 'cook' and kula 'eat', as modified from Mohammed (2001: 71). These decisions or processes are referred to as a language syllabus (cf. Nunan, 1997: 194). It is a syllabus because it is a blueprint, as Richards (2013) states about what is expected to happen in L2 classrooms. It needs to be pointed out that there are several syllabi with varying designs (cf. Breen, 1987a, 1987b, 2001), based on the designers' understanding on the nature of language and their associated theories of language teaching and learning.

Regarding the process, Richards $(2013: 6,11)$ states that process refers to the way learning practices are carried out in the language classroom. The process, also known as the methodology, entails the procedures and activities that language teachers employ in their classes. Language methodologies are derived from the advanced theories that mainly inform both the nature of a language and the dynamics of teaching and learning L2s (cf. Richards \& Schmidt, 2010: 363, on language teaching methods). One of the contemporary methodologies in L2 teaching and learning is task-based language teaching (TBLT). According to Ellis et al., (2002: 213), one of the TBLT approaches of teaching is form-focused instruction, specifically, planned focus-on-form instruction (cf. Ellis, 2003: 65; Ellis, 2009: 223).

In this regard, Ellis et al., (2002: 420) define planned focus-on-form instruction as a type lesson 'designed to elicit the use of a specific linguistic form in the context'. The planned focus-on-form entails facets that are associated with the P-P-P approach (cf. Benati, 2013: 1415). In this respect, the first $P$ stands for presentation. This phase is obtained when the teacher presents to the learners the lesson in terms of the learning content - for instance, the Kiswahili verbs of Bantu origin, cheza, pika and kula. In this step, the teacher provides the learners with all they require to know about these verbs. For example, unlike verbs of Arabic origin, Mohammed (2001: 71) argues that all the stems of Kiswahili verbs of Bantu origin end with a. In addition, unlike the nine verb stems of the monosyllabic verbs, like the verb stems from other Bantu languages, Kiswahili verbs consist of two or more stems.

Richards (2013: 11) maintains that most learning units in L2 teaching models are provided to the learners from what the learners know to something new. For example, in the Ugandan contexts, Kiswahili verbs such as lima 'dig', nenda 'go' and zaa 'give birth' can be extended to learners before verbs such as lia 'cry' and kuja 'come' are introduced. This is because, in Uganda, while the three former verbs are more or less common in most Bantu languages, the two latter verbs are not.

The second $\mathrm{P}$ stands for practice. It follows the presentation stage. In the practice stage, Kiswahili teachers demonstrate to the learners how given syllables of verbs are pronounced. Then the teacher leads learners to pronounce the verbs until learners are able to pronounce them as required by the teacher. In this stage, learners are tasked to do several exercises such as questions-and-answers, transformation, repetitions and chains of verbs to ensure that they articulate the verbs correctly (cf. Baleghizadeh, 2012: 155; Benati, 2013: 15).

The last $\mathrm{P}$ stands for production. Production is the last stage of the planned focus-on-form lessons. In this stage, learners are required to contextualise the verbs that they have practised to pronounce by using such verbs in either written or spoken form. Given that learners can produce and reproduce the verbs as required, it is likely that they can gradually master and learn the Kiswahili verbs. In the next lesson phase, the teacher can introduce a new topic or lesson, with a certain degree of similarity or connectedness with the verbs, such as adverbs 
(see Richards's (2013: 6) views on the mastery-oriented approach to teaching). Thus, adverbs such as sana 'loudly', vizuri 'nicely' and jana usiku 'last night', as modified from Mohammed (2001: 93), can be extended to the Kiswahili learners. Therefore, to connect these adverbs with some of the previously mentioned Kiswahili verbs, the following sentence structures can be realised.

1. Analia sana ' $\mathrm{S} / \mathrm{he}$ is crying loudly'.

2. Walienda jana usiku 'They went last night'.

3. Itacheza vizuri 'It will play nicely'.

Lastly, with regard to Richards' (2013: 7) components of a forward design dimension, the output is the last component. The output refers to the confirmation as to whether learning has taken place. This is more or less like the production stage discussed in the previous paragraph. The output is measured after a given period of instruction. There are several mechanisms for testing the required output by the learners. These include classroom exercises, either in written or in oral form. Teachers may want to ascertain whether, after rigorous teaching and learning, learners can, for instance, draw a distinction in accurately pronouncing verbs that end with two similar vowels, such as kaa 'sit', zaa 'give birth' and kataa 'refuse', from verbs that end with single vowel, such as kata 'cut'. In all this, teachers attempt to find out the general knowledge base that learners have acquired with regard to the articulation of the introduced Kiswahili verbs (cf. Richards, 2013: 9).

As we proceed to the concluding remarks of this paper, it is in order to refer to Richards' (2013: 13) final observations regarding the development of the dimensions for forward design. Richards (2013: 13) observes that, '[in] some contexts the planning and development of each stage in the curriculum development process is carried out by specialists who have expertise in each process.' Nevertheless, while describing the forward design dimension as an approach for specialists, with reference to Richards (2013: 13), Graves (2008: 150) observes that, given that different specialists will design particular steps of the above-explored dimensions, accurately aligning the above components is a challenge. This situation creates another dilemma in employing such a curriculum for effective learning practices in L2 classrooms (cf. Robinson, 2009: 194-195).

Thus, to address the challenges outlined in the above paragraph with regard to Kiswahili language teaching, there is a need to empower Kiswahili subject teachers to utilise the available curriculum development materials so that the whole process (from input through to output) of syllabus design and development, as advanced by Richards (2013), is done by a single teacher or a group of teachers in a given school following commonly agreed-upon criteria (cf. Ellis, 2010: 187; Freeman \& Johnson, 1998). Kiswahili teachers who emulate this strategy to syllabus design attempt to position themselves to fulfil teaching responsibilities, given the utility value of their contributions to the schools' subject curriculum, which is envisaged to be felt particularly in schools where Kiswahili is provided for in timetables without syllabi to facilitate the actual teaching.

\section{CONCLUSION}

This theoretical paper has argued that the NCDC's delay in distributing Kiswahili syllabi in primary schools has led Kiswahili teachers to design school-based syllabi. The scholarly literature expresses the view that, for such syllabi to be in line with contemporary trends in syllabus design and correspond well with instructional materials such as textbooks, the advice 
(input) of language specialists is needed. Thus, to contextualise these proposals, the paper has explored and demonstrated to Kiswahili teachers the application of Richards' (2013) forward design dimension to curriculum/syllabus design. This application serves two purposes. Firstly, it can assist Kiswahili teachers in updating their existing school-based syllabi in order to strengthen the teaching and learning of Kiswahili in schools. Similarly, this application can be used by other L2 teachers to start designing school-based syllabi that can be employed in their classrooms and schools.

In this regard, the paper advances the view that it is important that teachers have knowledge of these respective areas relevant to language teaching and learning, hence the ability to creatively introduce innovations in these respective areas of language teaching and learning, as stated in the paper. Subsequently, the paper recommends for similar studies to examine the sufficient actualisation of instructional materials and the teaching of Kiswahili, for example, in post-primary schools. This recommendation attempts to substantiate that there is a clear and viable realisation of Kiswahili instructional materials and their teaching and learning across the education system within and outside Ugandan contexts.

\section{REFERENCES}

ASHTON, EO. 1987. Swahili grammar: including intonation (reprinted). Essex: Longman.

BALEGHIZADEH, S. 2012. Grammatical syllabus and EFL textbooks: the need for consciousnessraising activities. Per Linguam, 28(1):111-116.

BENATI, AG. 2013. Issues in second language teaching. Sheffield: Equinox.

BREEN, MP. 1987a. Contemporary paradigms in syllabus design: part I. Language Teaching, 20(2):81-92.

BREEN, MP. 1987b. Contemporary paradigms in syllabus design: Part II. Language Teaching, 20(3):157-174.

BREEN, MP. 2001. Syllabus design. In D Nunan \& R Carter (Eds), The Cambridge guide to teaching English to speakers of other languages. New York: Cambridge University Press. 151-159.

ELLIS, R. 2003. Designing a task-based syllabus. RELC Journal, 34(1):64-81.

ELLIS, R. 2010. Second language acquisition, teacher education and language pedagogy. Language Teaching, 43(2):182-201.

ELLIS, R, H BASTURKMEN \& S LOEWEN. 2002. Doing focus-on-form. System, 30(4):419-432.

ELLIS, R \& N SHINTANI. 2014. Exploring language pedagogy through second language acquisition research. London: Routledge.

FINNEY, D. 2002. The ELT curriculum: a flexible model for a changing world. In JC Richards \& WA Renandya (Eds), Methodology in language teaching: an anthology of current practice. Cambridge: Cambridge University Press. 69-79.

FREEMAN, D \& KE JOHNSON. 1998. Reconceptualizing the knowledge-base of language teacher education. TESOL Quarterly, 32(3):397-417.

GALVÃO, C, C FARIA, S BAPTISTA \& M FREIRE. 2017. Curriculum conception, implementation \& evaluation: an experience. In B Akpan (Ed.), Science education: global perspective. Switzerland: Springer. 253-272.

GRAVES, K. 2008. The language curriculum: A social contextual perspective. Language Teaching, 41(2):147-181.

GROGAN, L. 2009. Universal primary education and school entry in Uganda. Journal of African Economies, 18(2):183-211.

HABWE, J \& P KARANJA. 2004. Misingi ya sarufi ya Kiswahili [Foundations of the Kiswahili grammar]. Nairobi: Phoenix Publishers.

ISINGOMA, B. 2016. Languages in East Africa: policies, practices and perspectives. Sociolinguistic Studies, 10(3):433-454. DOI: https://doi.org/10.1558/sols.v10i3.27401 
JJINGO, C. 2018. Cognitive task analysis in task-based syllabus design for the teaching and learning of Kiswahili as a second language in Ugandan secondary schools. Unpublished PhD dissertation. Stellenbosch: Stellenbosch University.

JJINGO, C \& M VISSER. 2017. The Ssenteza Kajubi legacy: the promotion of teaching Kiswahili in Uganda. Africology: The Journal of Pan African Studies, 10(9):1-14.

KIANGO, JG. 2005. Tanzania's historical contribution to the recognition and promotion of Swahili. Africa \& Asia, 5:157-166.

KRAHNKE, K. 1987. Approaches to syllabus design for foreign language teaching. Englewood Cliffs: Prentice-Hall.

LONG, MH \& G CROOKES. 1993. Units of analysis in syllabus design: the case for a task. In G Crookes \& SM Gass (Eds), Tasks in a pedagogical context: Integrating theory and practice. Clevedon: Multilingual Matters. 9-54.

MASSAMBA, DPB, YM KIHORE \& JI HOKORORO. 2012. Sarufi miundo ya Kiswahili sanifu (SAMIKISA): sekondari na vyuo [Grammatical structures of standard Kiswahili: secondary schools and colleges] (4th ed.). Dar es Salaam: Taasisi ya Uchunguzi wa Kiswahili.

MASSAMBA, DPB, YM KIHORE \& YP MSANJILA. 2004. Fonolojia ya Kiswahili sanifu (FOKISA): sekondari na vyuo [The phonology of standard Kiswahili: secodary schools and colleges]. Dar es Salaam: Taasisi ya Uchunguzi wa Kiswahili.

MBAABU, I. 2007. Historia ya usanifishaji wa Kiswahili [The history of standardizing Kiswahili] (2nd ed.). Dar es Salaam: Taasisi ya Uchunguzi wa Kiswahili.

MINISTRY OF EDUCATION AND SPORTS. 2004. Education sector strategic plan 2004-2015. Kampala: Education Planning Department. Available from http://planipolis.iiep.unesco.org/sites/planipolis/files/ressources/uganda_essp_2004_2015.pdf [Accessed: 15 June 2018].

MINISTRY OF EDUCATION AND SPORTS. 2017. Education and sports sector strategic plan 2017/18-2019/20. Kampala: Ministry of Education and Sports. Available from http://www.education.go.ug/files/downloads/EDUCATION\%20AND\%20SPORTS\%20SECTO R\%20STRATEGIC\%20PLAN.pdf [Accessed: 12 March 2018].

MOHAMMED, MA. 2001. Modern Swahili grammar. Nairobi: East African Publishers.

MPIRANYA, F. 2015. Swahili grammar and workbook. New York: Routledge.

MSANJILA, YP. 2005. Hali ya Kiswahili katika shule za sekondari Tanzania: udhalilishaji wa lugha ya Taifa? [The state of Kiswahili in Tanzania's secondary schools: humiliation of national language?] Swahili Forum, 12:205-218.

MUKAMA, R. 2009. Theory and practice in language policy: the case of Uganda. Kiswahili, 72(1):68-10.

MULUMBA, MB \& FM MASAAZI. 2012. Challenges to African development: the medium of instruction in Uganda's education system. Pedagogy, Culture \& Society, 20(3):435-450. DOI: https://doi.org/10.1080/14681366.2012.712056

NATIONAL CURRICULUM DEVELOPMENT CENTRE (NCDC). 2012. Teachers piloting Kiswahili in Uganda: report on P.5 phase I Kiswahili teachers'orientation. Kampala: NCDC.

NUNAN, D. 1991. Communicative tasks and the language curriculum. TESOL Quarterly, 25(2):279295.

NUNAN, D. 1997. Designing and adapting materials to encourage learner autonomy. In P Benson \& $\mathrm{P}$ Voller (Eds), Autonomy \& independence in language learning. London: Longman. 192-203.

NUNAN, D. 2004. Task-based language teaching (revised). Cambridge: Cambridge University Press.

NUNAN, D. 2006. Task-based language teaching in the Asia context: defining 'task'. In P Robertson \& J Jung (Eds), Special conference proceedings volume: task-based learning in the Asian context. Tortola: Asian EFL Journal Press. 12-18.

PAWLIKOVÁ-VILHANOVÁ, V. 1996. Swahili and the dilemma of Ugandan language policy. Asian and African Studies, 5(2):158-170.

PAWLIKOVÁ-VILHANOVÁ, V. 2004. White fathers, Islam and Kiswahili in nineteenth-century Uganda. Asian and African Studies, 13(2):198-213.

REPUBLIC OF UGANDA. 1992. Government White Paper on the educational policy review 
commission report. Kampala: UPPC.

REPUBLIC OF UGANDA. 2005. The Constitution (Amendment) (No. 2) Act, 2005. Kampala: Government of Uganda. Available from https://www.legal-tools.org/doc/4870bd/pdf/ [Accessed: 4 October 2016].

REPUBLIC OF UGANDA. 2006. The Uganda national culture policy: a culturally vibrant, cohesive and progressive nation. Kampala: Ministry of Gender, Labour and Social Development. Available from http://ocpa.irmo.hr/resources/policy/Uganda_Culture Policy-en.pdf [Accessed: 4 October 2016].

REPUBLIC OF UGANDA. 2008a. Integrated English teaching syllabus: Uganda certificate of education: Senior 1-4. Kampala: National Curriculum Development Centre.

REPUBLIC OF UGANDA. 2008b. Kiswahili teaching syllabus: Uganda certificate of education: Senior 1-4. Kampala: National Curriculum Development Centre.

REPUBLIC OF UGANDA. 2014. Silabasi ya Kiswahili kidato cha tano na cha sita [Kiswahili syllabus for Senior five and six]: Uganda advanced certificate of education. Kampala: National Curriculum Development Centre.

REPUBLIC OF UGANDA. 2015a. Constitution of the Republic of Uganda 1995 (with amendment as at 24th August, 2015) (reproduced). Kampala: Law Development Centre.

REPUBLIC OF UGANDA. 2015b. Education statistical abstract 2015. Kampala: Ministry of Education, Science, Technology and Sports. Available from http://www.education.go.ug/files/downloads/Abstract2015.pdf [Accessed: 23 March 2017].

REPUBLIC OF UGANDA. 2016. Kiswahili teaching syllabus: Uganda certificate of education: Senior 1-4 (reprinted). Kampala: National Curriculum Development Centre.

RICHARDS, JC. 1984. Language curriculum development. RELC Journal, 15(1):1-29.

RICHARDS, JC. 1985. The context of language teaching. Cambridge: Cambridge University Press.

RICHARDS, JC. 2001. Curriculum development in language teaching. New York: Cambridge University Press.

RICHARDS, JC. 2006. Communicative language teaching today. New York: Cambridge University Press.

RICHARDS, JC. 2007. Material development and research: towards a form-focused perspective. In S Fotos \& H Nassaji (Eds.), Form-focused instruction and teacher education: Studies in honour of Rod Ellis. Oxford: Oxford University Press. 147-160.

RICHARDS, JC. 2008. Second language teacher education today. Regional Language Centre Journal, 39(2):158-177.

RICHARDS, JC. 2010. Competence and performance in language teaching. RELC Journal, 41(2):101122.

RICHARDS, JC. 2013. Curriculum approaches in language teaching: forward, central, and backward design. RELC Journal, 44(1):5-33.

RICHARDS, JC. 2015. The changing face of language learning: learning beyond the classroom. RELC Journal, 46(1):5-22.

RICHARDS, JC. 2017. Transmissive and transformative approaches to language teacher education. Indonesian Journal of English Language Teaching, 12(1):15-38.

RICHARDS, JC \& C LOCKHART. 1996. Reflective teaching in second language classrooms. Cambridge University Press.

RICHARDS, JC \& WA RENANDYA. (Eds). 2002. Methodology in language teaching: an anthology of current practices. Oxford: Oxford University Press.

RICHARDS, JC \& R REPPEN. 2014. Towards a pedagogy of grammar instruction. RELC Journal, 45(1):5-25.

RICHARDS, JC \& TS RODGERS. 1982. Method: approach, design and procedure. TESOL Quarterly, 16(2):153-168. DOI: https://doi.org/10.2307/3586789

RICHARDS, JC \& TS RODGERS. 2014. Approaches and methods in language teaching (3rd ed.). Cambridge: Cambridge University Press.

RICHARDS, JC \& R SCHMIDT. 2010. Longman dictionary of language teaching and applied linguistics (4th ed.). Edinburgh: Pearson.

ROBINSON, P. 2009. Syllabus design. In MH Long \& CJ Doughty (Eds), The handbook of language 
teaching. Oxford: Wiley-Blackwell. 294-310.

SIMONS, GF \& CD FENNIG. (Eds.). 2018. Ethnologue: languages of the world. Dallas, TX: SIL International. Available from https://www.ethnologue.com/language/swh/21 [Accessed: 4 February 2018].

SSEKAMWA, JC \& SME LUGUMBA. 2000. Developments and administration of education in Uganda (2nd ed.). Kampala: Fountain Publishers.

SSENTANDA, ME. 2016. Tensions between English medium and mother tongue education in rural Ugandan primary schools. In C Meierkord, B Isingoma \& S Namyalo (Eds), Ugandan English: its sociolinguistics, structure and uses in a globalising post-protectorate. Amsterdam: John Benjamins. 95-117.

SSENTANDA, ME \& J NAKAYIZA. 2017. 'Without English there is no future': the case of language attitudes and ideologies in Uganda. In AE Ebongue \& E Hurst (Eds), Sociolinguistics in African contexts: perspectives and challenges. Switzerland: Springer. 107-126.

TAMUSUZA, A. 2011. Leaving school early: the quest for universal primary education in Uganda. Journal of Statistique Africain, 11:110-151.

VANPATTEN, B. 2002. Communicative classrooms, processing instruction, and pedagogical norms. In SM Gass, K Bardovi-Harlig, SS Magnan \& J Walz (Eds.), Pedagogical norms for second and foreign language learning and teaching: studies in honour of Albert Valdman. Amsterdam: John Benjamins, 105-118.

WILBUR, ML. 2007. How foreign language teachers get taught: methods of teaching the methods course. Foreign Language Annals, 40(1):79-101.

\section{BIOGRAPHICAL NOTES}

Dr. Caesar Jjingo is an Assistant Lecturer in the Department of Humanities and Language Education, Makerere University. His research interests include, language policy and planning frameworks, Kiswahili second language pedagogies and material development, particularly, in task-based approaches. Email: caesarial@gmail.com

Marianna Visser is a Professor in the Department of African Languages, Stellenbosch University. Her research foci include, formal lexical semantics and morphosyntax, syntactic development in second language acquisition, complexity in task-based language learning and teaching, appraisal and evaluation in discourse analysis. Email: $\underline{\text { mwv@ sun.ac.za }}$ 